\title{
INFORMATION CONTENT OF INTER-TRANSACTION TIME: A STRUCTURAL APPROACH
}

\author{
Doojin RYU \\ College of Economics, Sungkyunkwan University, 25-2, Sungkyunkwan-ro, \\ Jongno-gu, Seoul 110-745, Republic of Korea \\ E-mail:doojin.ryu@gmail.com
}

Received 24 February 2013; accepted 09 May 2013

\begin{abstract}
This study examines the information role of inter-transaction time by employing a structural market microstructure model. By analyzing the intraday data of the KOSPI200 futures market, we find that the inter-transaction time (i.e., time between two consecutive trades) reveals significant information, and that fast trading is indicative of informed trading. This result remains robust when the effect of trade size is incorporated into the model. Our regression analysis indicates that the information role of inter-transaction time becomes more important when informed trading is less concentrated, liquidity is lower, and the market is more volatile.
\end{abstract}

Keywords: information content, informed trading, inter-transaction time, KOSPI200 futures, market microstructure, structural model.

JEL Classifications: G10, G15.

\section{Introduction}

The information contained in trade-related variables such as trade size, trade direction, and trading intensity has been continuously studied by market microstructure research. The empirical findings, however, remain inconsistent. For example, among studies that examine the information role of trade size, some argue that large-sized trades carry higher-quality information than small-sized trades (Easley et al. 1997; Easley, O'Hara 1987; Holthausen et al. 1990; Lin et al. 1995). Others have the opposite view, insisting that smaller trades are more informative because they often include strategic trades by informed investors who split their orders (Anand, Chakravarty 2007; Barclay, Warner 1993; Chakravarty 2001; Kim, Ryu 2012; Ryu 2012a). Another strand of research focuses on the information contained in the trade direction. Most of this research claims that buy trades are more informative than sell trades due to reasons such as market frictions and the asymmetric payoff structures of financial assets (Ahn et al. 2010; Easley et al. 1996). One study by Ryu (2013), however, reports that sell trades can be more informative in the absence of frictions and asymmetries. 
In contrast to the abundance of studies on trade size and trade direction, there is relatively little research on market microstructure addressing the information role of time between trades. Similar to trade size and direction, the inter-transaction time (i.e., time between trades) is not likely to be randomly decided, but rather is determined by the strategic decisions of informed investors and liquidity traders, and the interactions among them. Accordingly, the inter-transaction time can carry information. There is little consensus, however, on the significance of the information role of inter-transaction time. Even the hypotheses suggested by foundational microstructure research can be interpreted in various ways regarding the implications of inter-transaction time. According to the hypothesis of Admati and Pfleiderer (1988), informed investors time their trades and submit orders when markets are highly liquid. This behavior results in higher trading intensity (i.e., shorter inter-transaction time), implying a higher proportion of informed traders and more informative trades. On the other hand, a high concentration of informed investors may also crowd out liquidity traders. If this crowding effect is significant, then the trading intensity becomes low due to the decreased liquidity, and we observe a positive association between informed trading and inter-transaction time. If traders strategically behave as described in Parlour (1998), Foucault (1999), and Hoffmann (2014), then the situation becomes more complicated, and at least a priori, we are not sure about the true information content of inter-transaction time. Consequently, we cannot determine whether or not a higher trading intensity indicates the prevalence of informed trading.

The following empirical studies have also suggested opposing opinions about the information content of inter-transaction time. One strand of research supports the view that fast trading implies informed trading (Chen et al. 2008; Furfine 2007; Liu, Maheu 2012; Spierdijk 2004; Xu et al. 2006). This line of studies argues that the permanent price impact of trades generally increases as the inter-transaction time decreases. These studies assume that, when informed investors try to trade large amounts to increase their profits, high trading intensity is closely related to the informed trading and thereby incurs a larger permanent impact on asset prices. Another strand of research, including Grammig et al. (2011) and Beltran-Lopez et al. (2012), finds a positive association between inter-transaction time and information content. These studies insist that fast trading is largely related to noisy trading, rather than informed trading. In addition, considering that the information content of inter-transaction time depends on the interactions between informed investors and liquidity traders, as well as on market structure, the role of inter-transaction time is still open to empirical debate. To uncover all the related mechanisms, a variety of in-depth studies on global markets are needed.

Previous studies not only provide inconsistent views on the information content of intertransaction time, but also most of them depend on a simple VAR model developed by Dufour and Engle (2000), which can result in biased results due to their trade-event filtering. In contrast to previous studies, which employ the model of Dufour and Engle and yield unidirectional results, we examine the issue using a more sophisticated structural model to effectively handle real-time transaction data. Further motivation for this study is that most existing studies cover only the stock markets of developed nations. 
However, some constraints (e.g., short-sale constraints) in these stock markets impede exact identification of the true information effect of inter-transaction time.

Motivated by these considerations, we re-examine the information content of intertransaction time in the KOSPI200 futures market, which is one of the most liquid futures markets in the world ${ }^{1}$. Although some recent studies investigate this issue in emerging stock markets (Chen et al. 2008; Liu, Maheu 2012), little is known about the derivatives markets. Further, there are no short-sale restrictions and no buy-sell asymmetries in futures trades (Ryu 2013). These characteristics make it possible to investigate the information role of inter-transaction time without the involvement of biases and errors. This study creates a structural model by modifying the MRR model (Madhavan et al. 1997) to consider the elapsed time between two consecutive trades. We also extend the model to incorporate the effect of trade size when estimating model parameters, considering that informed investors can freely choose their trade frequencies and trade sizes in the futures market ${ }^{2}$. Thus, our extended model captures two dimensions of liquidity, which are trade size and trade frequency.

The empirical results in this study support the hypothesis that fast trading is clearly indicative of informed trading in the futures market. We find that the time between trades has significant information value and is negatively related to the informed trading. Controlling for trade size, the results of this analysis remain the same. Our regression analysis suggests that inter-transaction time is more informative when the permanent impact due to informed trading is smaller, liquidity is lower, and the futures market is more volatile.

\section{KOSPI200 futures}

The KOSPI200 futures market is definitely one of the most liquid index futures markets. Further, the market exhibits a unique investor participation rate in the dominance of individual investors ${ }^{3}$. In addition to these characteristics that make our research more valuable and interesting, the futures market provides an ideal setting to investigate the information role of inter-transaction time for several reasons, as follows.

First, there is no buy-sell asymmetry, which often exists in stock markets because of the short-sale constraints. Buy-sell asymmetry distorts the information contained in trades. When there is positive information, informed traders eagerly buy stocks, and as a result, the trading intensity increases. On the other hand, due to the short-sale constraints, investors who possess negative information often confront a restriction on selling stocks

\footnotetext{
${ }^{1}$ Due to the rapid growth of the KOSPI200 options market and synergistic effects (Ahn et al. 2008; Guo et al. 2013; Han et al. 2012; Kim, Ryu 2015b; Lee, Ryu 2014; Ryu et al. 2015), the futures market also becomes the top-tier index derivatives market in the world.

${ }^{2}$ Instead of submitting large orders, informed investors often fragment their trades to camouflage identification of their trades and their trading intentions. This trading strategy is called "stealth-trading".

${ }^{3}$ See Han et al. (forthcoming), Kim et al. (forthcoming), Kim and Ryu (2015a), and Lee et al. (2015), among others.
} 
if they do not own the stocks. Under this condition, long inter-transaction time indicates two possibilities - either lack of information or the existence of negative information which are difficult to distinguish from one another in stock markets (Diamond, Verrecchia 1987). In contrast to this equity trading, all futures traders can freely submit orders in both directions at any time. That is, the futures traders can make sell trades regardless of whether or not they have a long futures position. As a result, we can directly interpret the information contents of trade-related variables in the index futures market. Second, the definition of information superiority in the KOSPI200 futures market is different from the definition of information superiority in equity markets. In equity markets, informed investors make transaction decisions based on private information, which puts the investors in superior positions for relatively long stretches of time. In contrast, in the index futures market, investors achieve information advantages by processing public and market-wide information faster than other traders, and by acquiring trading skills and knowledge. Such advantages can disappear quickly if the investors do not immediately exploit the information. Thus timing is a very important factor in the futures market, and it follows that inter-transaction time holds meaningful information. Third, the level of market frictions, which might impede the detection of the information effect of trades, is quite low in the KOSPI200 futures market.

A long-standing argument exists among market practitioners and academics about the role of KOSPI200 futures trading, because many continue to believe that the market is still dominated by noisy and uninformed trading. If this noisy trading is indeed prevalent, then fast trading might be merely the result of noisy and/or impatient trading, leading to the conclusion that higher trading intensity is not, in fact, informative. To investigate this debated issue, in-depth study is urgently required in the futures market.

\section{Models}

The basic objective of the MRR model is to deconstruct the effects of an incoming trade on the asset price process into two parts: the permanent price impact component related to informed trading, and the temporary price effect component related to uninformed and/or liquidity trading. The MRR framework has some distinct advantages. First, if buy and sell trades are accurately classified, then the MRR model provides reliable estimation results. Second, because it does not assume there to be inventory holding costs, the model can be applied to order-driven markets in which concepts related to the dealers and the inventory holding costs are difficult to define.

Despite these advantages, the original MRR model has a critical weakness. The model assumes that the time between trades is exogenously determined, and that the size of each trade is exactly the same. In reality, however, the inter-transaction time and trade size are not irrelevant to market behavior and to the information contents embedded in the trades. Therefore, we propose new structural models by extending the MRR model to incorporate the effects of inter-transaction time and trade size.

Because the structural model directly measures asset price changes and separately considers the effects of exogenous shocks, our extended models can effectively capture the 
information content of inter-transaction time without regard to such confounding effects as might be caused by the model of Dufour and Engle (2000). Under the advantageous MRR framework, we propose a structural model that incorporates inter-transaction time (the time-dependent MRR (T-MRR) model), as does a model by Grammig et al. (2011). Equation (1) describes the changes in the fundamental asset value, based on the unexpected portion of incoming trades and market innovation:

$$
\Delta \mu_{t} \equiv \mu_{t}-\mu_{t-1}=\left(\alpha_{0}+\alpha_{1} \ln \left(T_{t}\right)\right)\left(x_{t}-E\left[x_{t} \mid x_{t-1}\right]\right)+\varepsilon_{t} .
$$

Here, $x_{t}$ is the trade indicator variable, which takes a value of $1(-1)$ if the initiating trade at time $t$ is a buy (sell) trade. $\mu_{t}$ is the fundamental asset value and $T_{t}$ is the time between two consecutive trades at time $t-1$ and time $t$. The error term $\varepsilon_{t}$ describes innovation of public beliefs. $\alpha_{0}+\alpha_{1} \ln \left(T_{t}\right)$ represents the size of the permanent price impact incurred by the trade at time $t$ (i.e., the $t^{\text {th }}$ trade). For this permanent price impact of the $t^{t h}$ trade, $\alpha_{0}$ is the portion that is independent of inter-transaction time, and $\alpha_{1} \ln \left(T_{t}\right)$ is the portion that is directly dependent on the inter-transaction time. The parameter $\alpha_{1}$ captures the information content of inter-transaction time. The value of the conditional expectation $\mathrm{E}\left[x_{t} \mid x_{t-1}\right]$ is equal to $\rho x_{t-1}$, where $\rho$ is the serial correlation of the trade indicator variable.

Equation (2) explains that the transaction price, $P_{t}$, is determined by the post-trade fundamental asset value, the temporary price effect component of the incoming trade, and the residual:

$$
P_{t}=\mu_{t}+\left(\beta_{0}+\beta_{1} \ln \left(T_{t}\right)\right) x_{t}+\xi_{t}
$$

Here, $\beta_{0}+\beta_{1} \ln \left(T_{t}\right)$ represents the size of the temporary price effect component of the trade at time $t$, which is independent from the change in the fundamental value. If a trade is not made by an informed trader, or if the information quality of the trade is low, then the changed level of the asset price incurred by the trade will not be permanent. The price will soon return to the fundamental asset value. For this temporary price effect of the $t^{\text {th }}$ trade, $\beta_{0}$ is the portion that is independent of the inter-transaction time, and $\beta_{1} \ln \left(T_{t}\right)$ is the portion that depends on the inter-transaction time. $\beta_{1}$ captures the effect of the inter-transaction time on the temporary portion. The residual $\xi_{t}$ measures the effect of rounding errors.

Equations (1) and (2) yield Equation (3), which is used to set up the GMM estimation equations in Equation (4) 4 :

$$
\begin{aligned}
& \Delta P_{t} \equiv P_{t}-P_{t-1}=\left(\alpha_{0}+\beta_{0}\right) x_{t}-\left(\rho \alpha_{0}+\beta_{0}\right) x_{t-1}+\left(\alpha_{1}+\beta_{1}\right) x_{t} \ln \left(T_{t}\right)- \\
& \beta_{1} x_{t-1} \ln \left(T_{t-1}\right)-\rho \alpha_{1} x_{t-1} \ln \left(T_{t}\right)+v_{t}, \text { where } v_{t}=\varepsilon_{t}+\xi_{t}-\xi_{t-1} .
\end{aligned}
$$

\footnotetext{
$4 v_{0}$ is a constant drift term.
} 


$$
E=\left[\begin{array}{l}
x_{t}\left(x_{t}-\rho x_{t-1}\right) \\
v_{t}-v_{0} \\
x_{t}\left(v_{t}-v_{0}\right) \\
x_{t-1}\left(v_{t}-v_{0}\right) \\
x_{t} \ln T_{t}\left(v_{t}-v_{0}\right) \\
x_{t-1} \ln T_{t-1}\left(v_{t}-v_{0}\right) \\
x_{t-1} \ln T_{t}\left(v_{t}-v_{0}\right)
\end{array}\right]=0 .
$$

Although the central concern of this study is inter-transaction time, we know that market liquidity is generally described as not only trading frequency, which is the number of trades within a fixed time or the average inter-transaction time between consecutive trades, and also trading volume, which is the size of each trade. An investor has two options when trading a large amount. The first option is to make a single or a few large trades, and the second is to make a series of numerous small trades by fragmenting the trades. Accordingly, in order to examine the issues related to inter-transaction time, we have to control the trade size, another dimension of liquidity. The following equations explain how the effects of trade size are incorporated into the MRR framework:

$$
\mu_{t}=\mu_{t-1}+\left(\alpha_{0}+\alpha_{1} \ln \left(T_{t}\right)+\alpha_{2} \sqrt{ } S_{t}\right)\left(x_{t}-E\left[x_{t} \mid x_{t-1}\right]\right)+\varepsilon_{t} .
$$

In Equation (5), $S_{t}$ is the size of the $t^{t h}$ trade. $\alpha_{0}+\alpha_{1} \ln \left(T_{t}\right)+\alpha_{2} \sqrt{ } S_{t}$ represents the size of the permanent price impact caused by the trade at time $t$. For the permanent price impact of the $t^{t h}$ trade, $\alpha_{0}$ is the portion that is independent of the inter-transaction time and trade size, $\alpha_{1} \ln \left(T_{t}\right)$ is the portion that depends on the inter-transaction time, and $\alpha_{2} \sqrt{ } S_{t}$ is the portion that depends on the size. That is, $\alpha_{1}$ and $\alpha_{2}$ capture the information contents of inter-transaction time and of trade size, respectively.

Equation (6) also indicates that the temporary price effect is comprised of three parts, including the time-independent and size-independent portion $\left(\beta_{0}\right)$, the time-dependent portion $\left(\beta_{1} \ln \left(T_{t}\right)\right)$, and the size-dependent portion $\left(\beta_{2} \sqrt{ } S_{t}\right)$ :

$$
P_{t}=\mu_{t}+\left(\beta_{0}+\beta_{1} \ln \left(T_{t}\right)+\beta_{2} \sqrt{ } S_{t}\right) x_{t}+\xi_{t} .
$$

By combining Equations (5) and (6), a more complicated estimation equation is derived in Equation (7), as follows:

$$
\begin{aligned}
& \Delta P_{t}=\left(\alpha_{0}+\beta_{0}\right) x_{t}-\left(\rho \alpha_{0}+\beta_{0}\right) x_{t-1}+\left(\alpha_{1}+\beta_{1}\right) x_{t} \ln \left(T_{t}\right)-\beta_{1} x_{t-1} \ln \left(T_{t-1}\right)- \\
& \rho \alpha_{1} x_{t-1} \ln \left(T_{t}\right)+\left(\alpha_{2}+\beta_{2}\right) x_{t} \sqrt{ } S_{t}-\beta_{2} x_{t-1} \sqrt{ } S_{t-1}-\rho \alpha_{2} x_{t-1} \ln \left(T_{t}\right)+v_{t}, \\
& \text { where } v_{t}=\varepsilon_{t}+\xi_{t}-\xi_{t-1} .
\end{aligned}
$$

We call this further extended MRR model a time-dependent and size-dependent MRR (TS-MRR) model. The GMM equations of the TS-MRR model are given in Equation (8): 


$$
E=\left[\begin{array}{l}
x_{t}\left(x_{t}-\rho x_{t-1}\right) \\
\mathrm{v}_{t}-\mathrm{v}_{0} \\
x_{t}\left(\mathrm{v}_{t}-\mathrm{v}_{0}\right) \\
x_{t-1}\left(\mathrm{v}_{t}-\mathrm{v}_{0}\right) \\
x_{t} \ln T_{t}\left(\mathrm{v}_{t}-\mathrm{v}_{0}\right) \\
x_{t-1} \ln T_{t-1}\left(\mathrm{v}_{t}-\mathrm{v}_{0}\right) \\
x_{t-1} \ln T_{t}\left(\mathrm{v}_{t}-\mathrm{v}_{0}\right) \\
x_{t} \sqrt{S_{t}}\left(\mathrm{v}_{t}-\mathrm{v}_{0}\right) \\
x_{t-1} \sqrt{S_{t-1}}\left(\mathrm{v}_{t}-\mathrm{v}_{0}\right) \\
x_{t-1} \sqrt{S_{t}}\left(\mathrm{v}_{t}-\mathrm{v}_{0}\right)
\end{array}\right]=0
$$

\section{Estimation results of the T-MRR}

This section provides the empirical findings related to the information content of intertransaction time. The sample data is real-time trade and quote data of KOSPI200 futures from January 2003 to September 2006. The futures have maturity dates every three months. To eliminate the possible effects of maturity biases on the model estimation, we construct fifteen futures series, each covering a three-month period.

Table 1 shows the estimation results for the T-MRR model for each futures series. The table reports the estimated model parameters $\left(\alpha_{0}, \alpha_{1}, \beta_{0}, \beta_{1}\right)$ and their corresponding $t$ statistics (in parentheses), and presents the spread components $\left(P I=\alpha_{0}+\alpha_{1} \overline{\ln T}, T E=\right.$ $\beta_{0}+\beta_{1} \overline{\ln T}$ ) measured in percentage of futures prices 5 . The permanent price impact component $(P I)$ has an average value of 0.00125 points, corresponding to $0.00103 \%$ of the futures transaction price ${ }^{6}$. The temporary price effect component $(T E)$ has an average value of 0.01930 points, which is $0.01715 \%$ of the futures price. The average value of $\gamma(=P I /(P I+T E))$ is $6.2 \%$, which indicates that about $6.2 \%$ of the futures spread is explained by informed trading in the futures market. The significance of the estimated parameters $\alpha_{0}, \alpha_{1}, \beta_{0}$, and $\beta_{1}$ indicates that both time-related and time-independent components are important in explaining the components of the futures spread and the intraday price formation. Of these parameters, we are most concerned with $\alpha_{1}$, whose sign and magnitude have direct implications on the information content of inter-transaction time. All $\alpha_{1}$ estimates are negative and highly significant. That is, the permanent price impact component increases as the inter-transaction time gets shorter. This indicates that

\footnotetext{
${ }^{5}$ The average value of the $\rho$ estimates is $0.504 . \overline{\ln T}$ denotes the average value of the inter-transaction time in each futures series. The implied spared equals $2(P I+T E)$.

${ }^{6}$ The basic quoting unit of the futures market is the "point." One point corresponds to 500,000 Korean Won.
} 
fast trading is not related to noisy trading, but rather to informed trading. This finding supports the hypothesis that fast trading is indicative of informed trading in the futures market.

We provide some plausible explanations by relating the characteristics of the KOSPI200 futures market and index futures trading to the results in Table 1. To maximize their profit, informed investors in the futures market should trade quickly. Their situation is somewhat different from that of informed traders in equity markets, who can maintain long-term supremacy based on private or inside information. Since it takes a relatively long time for markets to realize such information and for stock prices to fully reflect the information, the private information-advantaged equity traders have no need to rush their trades. In fact, if they do, their profits may decrease due to the adverse price movements that their hasty trades might incur, as well as due to excessive transaction costs. In contrast, in the KOSPI200 futures market, the advantage of informed investors is based on faster information processing of public and market-wide information. If the futures traders do not trade before the market reacts to the widespread information, their opportunity will be gone. Therefore, futures traders implement fast trading to fully exploit their information superiority. Further, the abundant liquidity reinforces this effect. It is widely known that the average spread is close to the minimum tick size and the market

Table 1. Estimation results of the T-MRR

\begin{tabular}{|c|c|c|c|c|c|c|c|c|c|c|c|}
\hline \multirow[t]{2}{*}{ Series } & \multicolumn{2}{|c|}{$\alpha_{0}$} & \multicolumn{2}{|c|}{$\alpha_{1}$} & \multicolumn{2}{|c|}{$\beta_{0}$} & \multicolumn{2}{|c|}{$\beta_{1}$} & \multirow{2}{*}{$\frac{\text { PI }}{\% \times 100}$} & \multirow{2}{*}{$\frac{\mathrm{TE}}{\% \times 100}$} & \multirow{2}{*}{$\begin{array}{c}\gamma \\
\% \\
\end{array}$} \\
\hline & Coef & $f \times 100$ & Coef. & $\times 100$ & Coef & $f \times 100$ & Coef & 100 & & & \\
\hline 1 & 0.147 & (98.6) & -0.039 & $(48.6)$ & 2.123 & (811.0) & 0.030 & $(48.6)$ & 0.141 & 2.889 & 4.67 \\
\hline 2 & 0.117 & $(86.0)$ & -0.025 & $(32.3)$ & 118 & (840.9) & 0.025 & (1. & 0.118 & 49 & 3.95 \\
\hline 3 & 0.115 & (69.1) & -0.032 & $(36.6)$ & 2.089 & (623.4) & 0.031 & $(46.3)$ & 0.080 & 2. & 3.37 \\
\hline 4 & 0.122 & $(78.0)$ & -0.023 & $(26.9)$ & 2.015 & (637.8) & 0.023 & $(34.0)$ & 0.091 & 2.024 & 4.30 \\
\hline 5 & 0.137 & $(69.5)$ & -0.025 & $(25.0)$ & 1.956 & 496.5) & 0.025 & ) & 0.091 & 1.755 & 4.92 \\
\hline 6 & 0.191 & (106.9) & -0.030 & (30. & 1.906 & (650.8) & 0.018 & $(22.4)$ & 0 . & 1.825 & 7.67 \\
\hline 7 & 0.127 & $(86.2)$ & -0.021 & $(24.4)$ & 1.970 & (655.7) & 0.018 & $(26.2)$ & 0.105 & 1.992 & 5.00 \\
\hline 8 & 0.137 & $(84.9)$ & -0.022 & $(24.0)$ & 1.928 & (616.5) & 0.022 & $(31.2)$ & 0.103 & 1.762 & 5.55 \\
\hline 9 & 0.140 & (71.3) & -0.025 & $(23.7)$ & 1.857 & (467.5) & 0.023 & $(30.6)$ & 0.092 & 1.524 & 5.70 \\
\hline 10 & 0.156 & $(81.2)$ & -0.033 & $(33.8)$ & 1.871 & $(463.5)$ & 0.024 & $(32.1)$ & 0.099 & 1.531 & 6.08 \\
\hline 11 & 0.171 & (91.4) & -0.033 & $(32.0)$ & 1.758 & (486.4) & 0.026 & $(34.1)$ & 0.095 & 1.238 & 7.14 \\
\hline 12 & 0.200 & (109.8) & -0.030 & $(29.2)$ & 1.716 & (492.3) & 0.025 & $(29.2)$ & 0.105 & 1.082 & 8.86 \\
\hline 13 & 0.213 & (128.6) & -0.029 & $(29.4)$ & 1.713 & $(549.5)$ & 0.030 & $(37.9)$ & 0.106 & 1.000 & 9.57 \\
\hline 14 & 0.202 & (127.1) & -0.033 & $(35.3)$ & 1.757 & $(587.8)$ & 0.034 & $(43.3)$ & 0.097 & 1.025 & 8.64 \\
\hline 15 & 0.184 & (121.0) & -0.043 & $(50.5)$ & 1.744 & (503.7) & 0.045 & $(58.6)$ & 0.082 & 1.047 & 7.24 \\
\hline erage & 0.157 & $(94.0)$ & -0.030 & $(32.1)$ & 1.901 & (592.2) & 0.027 & $(36.6)$ & 0.103 & 1.715 & 6.18 \\
\hline
\end{tabular}


depth is generally deep in the futures market. Informed investors can implement fast and extensive trading, enjoying abundant liquidity and relatively low transaction costs.

Our findings contrast with the theoretical prediction of Parlour (1998), who models investor behavior in order-driven markets and proposes the crowding-out effect. She insists that fast trading is dominated by impatient traders, and that limit orders are crowded out by the market orders of impatient and uninformed investors. More specifically, she argues that when a market has narrower spreads and becomes deeper (i.e., during a period of relatively more ample liquidity) compared to other periods, the benefits of limit orders decrease, and market orders come to dominate because impatient and liquidity traders abuse the aggressive orders. Even though this results in fast trading and high trading intensity, the trades in these types of periods contain little information content. However, the situation is somewhat different in the KOSPI200 futures market. Unlike stock markets, the futures market is basically liquid and characterized by tiny spreads and great market depth. In other words, in the futures market there might be no specific period that is more greatly conducive to impatient traders (i.e., every trading period can offer the abundant liquidity). Accordingly, rather than observing the crowding-out effect in specific time periods, we observe that fast trading by informed investors dominates in the futures market due to the unsustainable information superiority of futures traders who must act rapidly on time-sensitive information advantages in order to optimize profits.

Table 1 also reports that all estimates of $\beta_{1}$, which measures the time dependency in the temporary price effect component, are significantly positive. This is quite plausible because a long inter-transaction time corresponds to a decrease in liquidity. In less liquid market conditions, transaction costs increase, and thus the temporary price effect component and the futures spread should increase as well.

\section{Estimation results of the TS-MRR}

Table 2 presents the estimation results of the TS-MRR model for each futures series. The table reports the estimated model parameters $\left(\alpha_{0}, \alpha_{1}, \alpha_{2}, \beta_{0}, \beta_{1}, \beta_{2}\right)$ and their corresponding $t$-statistics (in parentheses), and presents the spread components $\left(P I=\alpha_{0}+\right.$ $\left.\alpha_{1} \overline{\ln T}+\alpha_{2} \sqrt{\bar{S}}, T E=\beta_{0}+\beta_{1} \overline{\ln T}+\beta_{2} \sqrt{\bar{S}}\right)$ and $\gamma(=P I /(P I+T E))^{7}$. All estimates of $\alpha_{1}$, the parameter that describes how the inter-transaction time affects the permanent price impact component, are highly significant and negative in the TS-MRR model. This indicates that the positive association between fast trading and informed trading still holds after controlling for the trade size. The positive values of the $\alpha_{2}$ estimates mean that large trades have higher permanent impacts on futures prices than smaller trades do. This confirms that the positive association between the informativeness of trades and their sizes, which is documented in previous studies on the KOSPI200 index derivatives markets (Ahn et al. 2010; Ryu 2013), holds, even after controlling the trade frequency.

\footnotetext{
${ }^{7} \bar{S}$ denotes the average trade size in each futures series.
} 


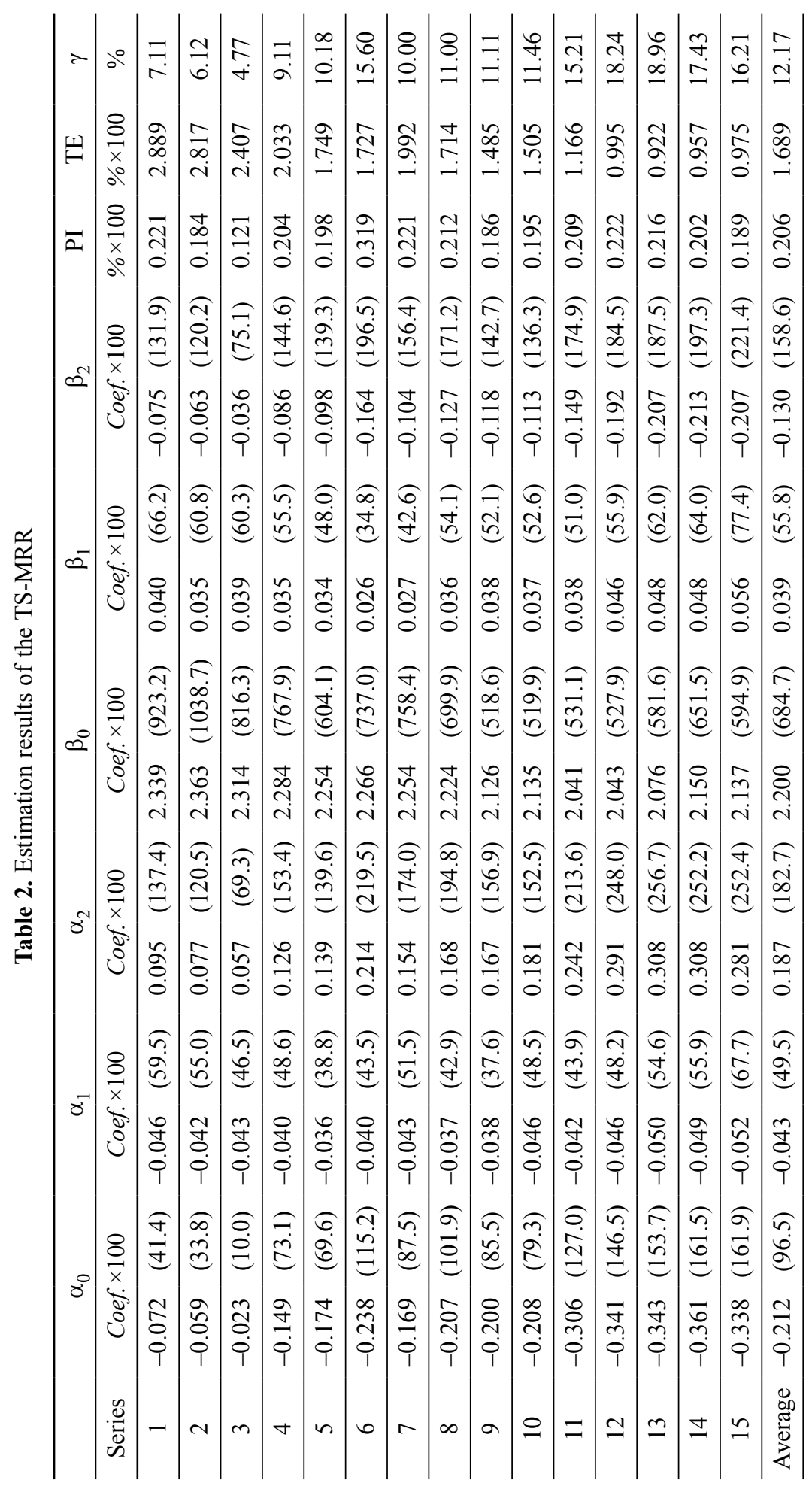




\section{Regression analysis}

The information content of inter-transaction time is possibly related to other microstructure variables such as the degree of informed trading, liquidity, trade size, volatility, time-to-maturity, and intraday time periods. To investigate this further, we set up the following regression equation:

$$
\begin{aligned}
& I_{i}=\gamma_{0}+\gamma_{1} \ln (\bar{T})_{i}+\gamma_{2} P I_{i}+\gamma_{3} \sqrt{\bar{S}_{i}}+\gamma_{4} \text { TTM }_{i}+\gamma_{5} \text { Volatility }_{i}+ \\
& \gamma_{6} \text { Intra }_{i}+\varepsilon_{i}, \text { where } i=1,2, \ldots, 5538 .
\end{aligned}
$$

To construct observations for the pooling regression, we estimate the T-MRR model and calculate the trading-related variables per one-hour trading intervals of each trading day. The total number of observations is 5,538. $I$ is an information measure, which gauges the information content of inter-transaction time and is expressed as $\alpha_{0}+$

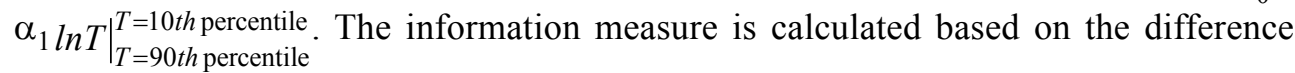
between the $10^{\text {th }}$ and $90^{\text {th }}$ percentiles of inter-transaction time in each interval. $\bar{T}$ is the average inter-transaction time, $P I\left(=\alpha_{0}+\alpha_{1} \ln (\bar{T})\right)$ is the average permanent price impact component, $\bar{S}$ is the average trade size, TTM is the time-to-maturity, Volatility is the realized volatility that is calculated using 5-minute log-returns, and Intra denotes a dummy variable that indicates the intraday interval of each trading day.

Table 3 presents the results of the regression analysis ${ }^{8}$. All explanatory variable estimates, except the TTM, are statistically significant. Each estimated coefficient has an economic implication depending on its sign, not its magnitude. The positive sign of $\ln (\bar{T})$ means that the inter-transaction time has greater information content as the trading frequency decreases (i.e., as trading slows down). The negative sign of $\sqrt{\bar{S}}$ is consistent with this indication. In sum, if other microstructure factors are held constant, such as the price impact due to informed trading, volatility, and intraday time period, then increased trading intensity (i.e., faster and larger trades) lowers the information content of the inter-transaction time. We can interpret this result in conjunction with

Table 3. Regression analysis

\begin{tabular}{lcc}
\hline & Coefficient & $t$-statistics \\
\hline Constant & 0.0031 & 30.19 \\
\hline $\ln (\bar{T})$ & $8.70 \mathrm{E}-05$ & 3.33 \\
\hline$P I$ & -0.9631 & -42.73 \\
\hline$\sqrt{\bar{S}}$ & -0.0005 & -16.01 \\
\hline$T T M$ & $-9.29 \mathrm{E}-07$ & -1.66 \\
\hline Volatility & 4.8283 & 14.52 \\
\hline Intra & $-2.61 \mathrm{E}-05$ & -4.29 \\
\hline
\end{tabular}

\footnotetext{
${ }^{8}$ The adjusted $R^{2}$ is about $27 \%$.
} 
our earlier finding that fast trading means informed trading, as follows. When informed trading dominates the futures market and fast trading prevails, there remains little to be additionally explained by inter-transaction time. Accordingly, the information role of inter-transaction time is diminished. On the other hand, when informed trading is not highly concentrated in the futures market, and consequently, relatively slower trading prevails, then the information role of inter-transaction time becomes important. In this case, inter-transaction time explains a substantial part of informed trading.

The negative sign of the $P I$ is also consistent with the above explanation. A large average price impact per trade indicates a season with higher amounts of informed trading. Therefore, the negative term indicates that, holding the trading activity and other microstructure factors constant, the information content of inter-transaction time becomes smaller (larger) as the degree of informed trading increases (decreases). That is, the high concentration of informed trading diminishes the role of inter-transaction time in providing additional information.

\section{Conclusions}

This is the first microstructure study to examine the information role of inter-transaction time in the intraday trading of KOSPI200 futures market. While most previous studies examine this issue under the straightforward (but potentially biased) VAR framework, this study employs more sophisticated structural microstructure models to effectively analyze the real-time transaction data in the order-driven emerging derivatives market. Our empirical results imply that the hypothesis "fast trading means informed trading" is valid in the futures market, which is characterized by ample liquidity and relatively low information asymmetry. We also find that the information content of inter-transaction time becomes greater when informed trading is less acute, liquidity is lower, and returns are more volatile in the futures market.

In addition to its academic contributions, this study provides implications for market practitioners. For example, futures traders can get some clues from fast trading. During periods of very fast trading, futures traders can postpone their trades to avoid transacting with better-informed traders and suffering losses. Our findings may offer guidance to policy makers who often regulate derivatives markets due to concerns about excessive trading and the severe money losses of uninformed domestic individual investors. The current regulation system relies on the price movements of derivatives assets, upon which regulation authorities base their determinations of whether or not the market is overheated. However, this study demonstrates that inter-transaction time should be taken into account as another indicator.

There are some limitations of this study. Our structural model does not consider the intraday market linkage between the KOSPI200 futures and options markets. The KOSPI200 options trading is closely related to the futures trading (Ryu, 2011), and until recently, the options market was the single most liquid derivatives market in the world. The analysis on the information role of inter-transaction time in the options market provides us additional economic implications. Future research can also exploit information on investor types. Institutional investors are generally better informed than individual 
investors in the KOSPI200 futures market (Ryu, 2012b, 2015). Considering that the information contents of orders vary depending on who submitted the orders, the analysis based on investor classifications expands our knowledge on the microstructure of the KOSPI200 futures market.

\section{Acknowledgments}

The author is grateful for the helpful comments and suggestions from Lars Norden.

\section{References}

Admati, A. R.; Pfleiderer, P. 1988. A theory of intraday trading patterns, Review of Financial Studies 1(1): 3-40. http://dx.doi.org/10.1093/rfs/1.1.3

Ahn, H.; Kang, J.; Ryu, D. 2008. Informed trading in the index option market: the case of KOSPI200 options, Journal of Futures Markets 28(12): 1118-1146.

http://dx.doi.org/10.1002/fut.20369

Ahn, H.; Kang, J.; Ryu, D. 2010. Information effects of trade size and trade direction: evidence from the KOSPI200 index options market, Asia-Pacific Journal of Financial Studies 39(3): 301339. http://dx.doi.org/10.1111/j.2041-6156.2010.01016.x

Anand, A.; Chakravarty, S. 2007. Stealth trading in option markets, Journal of Financial and Quantitative Analysis 42(1): 167-187. http://dx.doi.org/10.1017/S0022109000002234

Barclay, M. J.; Warner, J. B. 1993. Stealth trading and volatility: which trades move prices?, Journal of Financial Economics 34(3): 281-305. http://dx.doi.org/10.1016/0304-405X(93)90029-B

Beltran-Lopez, H.; Grammig, J.; Menkveld, A. J. 2012. Limit order books and trade informativeness, European Journal of Finance 18(9): 737-759.

http://dx.doi.org/10.1080/1351847X.2011.601651

Chakravarty, S. 2001. Stealth trading: which traders' trades move stock prices?, Journal of Financial Economics 61(2): 289-307. http://dx.doi.org/10.1016/S0304-405X(01)00063-0

Chen, T.; Li, J.; Cai, J. 2008. Information content of inter-trade time on the Chinese market, Emerging Markets Review 9(3): 174-193. http://dx.doi.org/10.1016/j.ememar.2008.02.006

Diamond, D.; Verrecchia, R. 1987. Constraints on short-selling and asset price adjustment to private information, Journal of Financial Economics 18(2): 277-311.

http://dx.doi.org/10.1016/0304-405X(87)90042-0

Dufour, A.; Engle, R. F. 2000. Time and the price impact of a trade, Journal of Finance 55(6): 2467-2498. http://dx.doi.org/10.1111/0022-1082.00297

Easley, D.; Kiefer, N. M.; O’Hara, M. 1997. The information content of the trading process, Journal of Empirical Finance 4(2-3): 159-186. http://dx.doi.org/10.1016/S0927-5398(97)00005-4

Easley, D.; Kiefer, N. M.; O’Hara, M.; Paperman, J. B. 1996. Liquidity, information, and infrequently traded stocks, Journal of Finance 51(4): 1405-1436.

http://dx.doi.org/10.1111/j.1540-6261.1996.tb04074.x

Easley, D.; O'Hara, M. 1987. Price, trade size, and information in securities markets, Journal of Financial Economics 19(1): 69-90. http://dx.doi.org/10.1016/0304-405X(87)90029-8

Foucault, T. 1999. Order flow composition and trading costs in a dynamic limit order market, Journal of Financial Markets 2(2): 99-134. http://dx.doi.org/10.1016/S1386-4181(98)00012-3

Furfine, C. 2007. When is inter-transaction time informative?, Journal of Empirical Finance 14(3): 310-332. http://dx.doi.org/10.1016/j.jempfin.2006.06.002

Grammig, J.; Theissen, E.; Wünsche, O. 2011. Time and price impact of a trade: a structural approach, Working paper. Universities of Tübingen and Mannheim. http://papers.ssrn.com/sol3/ papers.cfm?abstract_id $=968241$ 
Guo, B.; Han, Q.; Ryu, D. 2013. Is the KOSPI 200 options market efficient? Parametric and nonparametric tests of the martingale restriction, Journal of Futures Markets 33(7): 629-652. http://dx.doi.org/10.1002/fut.21563

Han, C.; Hwang, S.; Ryu, D. Market overreaction and investment strategies, Applied Economics (In Press).

Han, Q.; Guo, B.; Ryu, D.; Webb, R. I. 2012. Asymmetric and negative return-volatility relationship: The case of the VKOSPI, Investment Analysts Journal 76: 69-78.

http://dx.doi.org/10.1080/10293523.2012.11082551

Hoffmann, P. A. 2014. A dynamic limit order market with fast and slow traders, Journal of Financial Economics 113(1): 156-169. doi:10.1016/j.jfineco.2014.04.002

Holthausen, R. W.; Leftwich, R. W.; Mayers, D. 1990. Large-block transactions, the speed of response, and temporary and permanent stock-price effects, Journal of Financial Economics 26(1): 71-95. http://dx.doi.org/10.1016/0304-405X(90)90013-P

Kim, H.; Ryu, D. 2012. Which trader's order-splitting strategy is effective? The case of an index options market, Applied Economics Letters 19(17): 1683-1692.

http://dx.doi.org/10.1080/13504851.2012.665590

Kim, J. S.; Ryu, D. 2015a. Effect of the subprime mortgage crisis on a leading emerging market, Investment Analysts Journal 44(1): 20-42. http://dx.doi.org/10.1080/10293523.2015.994442

Kim, J. S.; Ryu, D. 2015b. Are the KOSPI 200 implied volatilities useful in value-at-risk models?, Emerging Markets Review 22(March): 43-64. http://dx.doi.org/10.1016/j.ememar.2014.11.001

Kim, J. S.; Ryu, D.; Seo, S. W. Corporate vulnerability index as a fear gauge? Exploring the contagion effect between US and Korean markets, Journal of Derivatives (In Press).

Lee, C.; Ryu, D. 2014. The volatility index and style rotation: evidence from the Korean stock market and VKOSPI, Investment Analysts Journal 43(79): 29-39.

http://dx.doi.org/10.1080/10293523.2014.11082566

Lee, J.; Kang, J.; Ryu, D. 2015. Common deviation and regime-dependent dynamics in the index derivatives markets, Pacific-Basin Finance Journal 33(June): 1-22.

http://dx.doi.org/10.1016/j.pacfin.2015.02.001

Lin, J.; Sanger, G. C.; Booth, G. G. 1995. Trade size and components of the bid-ask spread, Review of Financial Studies 8(4): 1153-1183. http://dx.doi.org/10.1093/rfs/8.4.1153

Liu, C.; Maheu, J. M. 2012. Intraday dynamics of volatility and duration: evidence from Chinese stocks, Pacific-Basin Finance Journal 20(3): 329-348.

http://dx.doi.org/10.1016/j.pacfin.2011.11.001

Madhavan, A.; Richardson, M.; Roomans, M. 1997. Why do security prices change? A transaction-level analysis of NYSE stocks, Review of Financial Studies 10(4): 1035-1064.

http://dx.doi.org/10.1093/rfs/10.4.1035

Parlour, C. A. 1998. Price dynamics in limit order markets, Review of Financial Studies 11(4): 789-816. http://dx.doi.org/10.1093/rfs/11.4.789

Ryu, D. 2011. Intraday price formation and bid-ask spread components: a new approach using a cross-market model, Journal of Futures Markets 31(12): 1142-1169.

http://dx.doi.org/10.1002/fut.20533

Ryu, D. 2012a. The effectiveness of the order-splitting strategy: an analysis of unique data, $A p$ plied Economics Letters 19(6): 541-549. http://dx.doi.org/10.1080/13504851.2011.587764

Ryu, D. 2012b. The profitability of day trading: an empirical study using high-quality data, Investment Analysts Journal 41(75): 43-54. http://dx.doi.org/10.1080/10293523.2012.11082543 Ryu, D. 2013. Price impact asymmetry of futures trades: trade direction and trade size, Emerging Markets Review 14: 110-130. http://dx.doi.org/10.1016/j.ememar.2012.11.005 
Ryu, D. 2015. The information content of trades: an analysis of KOSPI 200 index derivatives, Journal of Futures Markets 35(3): 201-221. http://dx.doi.org/10.1002/fut.21637

Ryu, D.; Kang, J.; Suh, S. 2015. Implied pricing kernels: an alternative approach for option valuation, Journal of Futures Markets 35(2): 127-147. http://dx.doi.org/ 10.1002/fut.21618

Spierdijk, L. 2004. An empirical analysis of the role of the trading intensity in information dissemination on the NYSE, Journal of Empirical Finance 11(2): 163-184.

http://dx.doi.org/10.1016/j.jempfin.2002.12.004

Xu, X. E.; Chen, P.; Wu, C. 2006. Time and dynamic volume-volatility relation, Journal of Banking and Finance 30(5): 1535-1558. http://dx.doi.org/10.1016/j.jbankfin.2005.05.011

Doojin RYU is a tenured professor at College of Economics, Sungkyunkwan University (SKKU), Seoul, Korea. He worked at the National Pension Service, Hankuk University of Foreign Studies, and Chung-Ang University. He is an associate editor of Emerging Markets Review and Investment Analysts Journal. He has published numerous articles in Applied Economics, Journal of Banking \& Finance, Journal of Business Ethics, Journal of Derivatives, Journal of Futures Markets, and Pacific-Basin Finance Journal. 